\title{
UCRL-TR-219216
}

LAWRENCE LIVERMORE N A TIO N A L LABORATORY

Earth Systems Science and Engineering

D. A. Rotman

February 22, 2006 
This document was prepared as an account of work sponsored by an agency of the United States Government. Neither the United States Government nor the University of California nor any of their employees, makes any warranty, express or implied, or assumes any legal liability or responsibility for the accuracy, completeness, or usefulness of any information, apparatus, product, or process disclosed, or represents that its use would not infringe privately owned rights. Reference herein to any specific commercial product, process, or service by trade name, trademark, manufacturer, or otherwise, does not necessarily constitute or imply its endorsement, recommendation, or favoring by the United States Government or the University of California. The views and opinions of authors expressed herein do not necessarily state or reflect those of the United States Government or the University of California, and shall not be used for advertising or product endorsement purposes.

This work was performed under the auspices of the U.S. Department of Energy by University of California, Lawrence Livermore National Laboratory under Contract W-7405-Eng-48. 


\section{Earth Systems Science and Engineering}

Providing the essential energy and water systems to support human needs while understanding and addressing their environmental consequences is a watershed problem for the $21^{\text {st }}$ century. The LLNL Earth System Science and Engineering Program seeks to provide the scientific understanding and technological expertise to help provide solutions at both global and regional scales. Our work is highly collaborative with universities, laboratories and industrial partners across the world and involves observational data, laboratory experiments, and numerical simulations.

The energy systems we have enjoyed for the last 100 years have resulted in the advanced standard of living in the developed world and a major emerging problem with climate change. Now we face a simultaneous realization that our reliance on fossil fuels is a source of conflict and economic disruption as well as causing potentially abrupt, even catastrophic global climate change.

The climate and energy problem is perhaps the greatest challenge ever faced by mankind. Fossil fuel remains the least expensive and most available source of energy and the basis of our economy. The use of fossil fuels, especially over the last 100 years has led to a $30 \%$ increase in $\mathrm{CO}_{2}$ in the atmosphere. The problem is growing. The population of the Earth will increase by several billion people in the next 50 years. If economic growth is to continue, the demand for energy is estimated to approximately double in the next 50 years so that we will need approximately $10 \mathrm{TW}$ more energy than the $15 \mathrm{TW}$ we use now. Much of this demand will come from the developing world where most of the population growth will occur and where advanced energy technology is not generally used.

The problem affects and is affected by a complex system of systems. The climate and energy problem will affect resources, social structure and the probability of increased conflict. No one person, no one nation, no one technology can solve the problem. There is no parallel precedent on which to model a solution. On these grounds, we have chosen to tackle four key tasks:

- Understanding the natural Earth system and anthropogenic systems examining key forcings and processes driving these systems and the interactions between systems

- Identify climate change impacts important to society and develop strategies and technologies to adapt to the climate change that is inevitable given past, current, and potential emissions

- Developing strategies and technologies to reduce/eliminate greenhouse gas emissions thereby mitigating climate change while generating energy that is economically and socially viable

- Engaging with appropriate economic, legal, social, and political structures to inform key decisions. 
Over the past year, we have created and organized the Earth Systems Science and Engineering program to address these tasks; our organization is show below

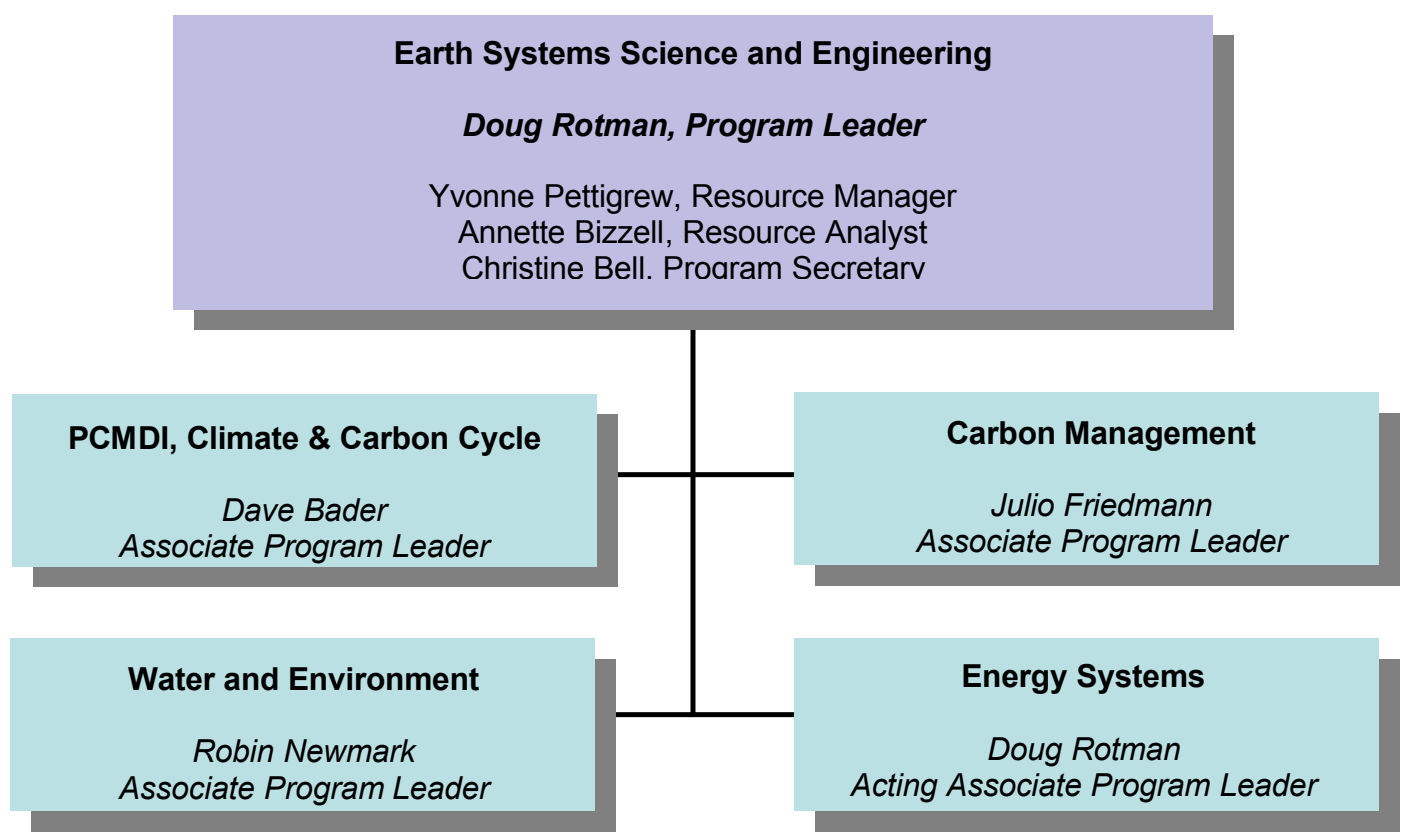

These four areas compromise the foundations of our programmatic activities. Those foundations plus interactions across the four areas are critical to addressing the tasks discussed above including,

Energy related greenhouse emissions and climate change

Climate change and environmental impacts (e.g. water) and adaptation strategies

Environmental understanding towards improved carbon sequestration

Carbon capture from energy systems

The FY2006 budget of the ESSE program is \$26.8M. The distribution of this funding across the four program areas is

PCMDI, Climate and Carbon Cycle: \$10.6M

Carbon Management: $\$ 1.2 \mathrm{M}$

Water and Environment: $\$ 7.2 \mathrm{M}$

Energy Systems: \$7.8M

This budget is made up of approximately 120 projects and programs ranging in size from a few tens of thousands to nearly 5 million dollars. The vast majority of projects $(\sim 70)$ are peer-reviewed single PI efforts that are funded at between $\$ 100$ and $\$ 500 \mathrm{~K}$. Just over $83 \%$ is DOE funding; primarily DOE Office of Science (SC), DOE Energy Efficiency and Renewable Energy (EERE) and DOE Environment, Safety, and Health (ESH). Internally funded LDRD (Laboratory Directed Research and Development) funds make 
up $5 \%$ as does funding from NASA. The State of California provides $2 \%$ of our funding; we are seeking that to grow in size and impact. The remaining budget $(\sim 5 \%)$ comes from a very long list of sponsors in the federal government (DOE/FE, DOE/EM, DOD, ...) and industry - these projects are critical to the execution of the entire ESSE program.

ESSE programmatic achievements and science accomplishments depend heavily on partnerships across the national and international community. The PCMDI, almost by definition, is centered as a focal point of climate simulation analysis across the international climate community. Indeed all ESSE programs are involved with federal, state, academic and industrial partners. Over the past year we have formed especially strong relationships with UC campuses at Berkeley, Davis, San Diego, Irvine, and Merced. Additionally, aligned with a LLNL funded initiative, we have expanded our partnership with the State of California, with special focus on the California Energy Commission (CEC), Department of Water Resources (DWR), and many other organizations in the State of California. Especially within the Carbon Management program, we have also engaged in a series of industrial partnerships in individual projects as well as an industry-wide "Joint Industrial Partnership" (JIP) aimed at enabling science insight in geochemistry and geomechanics via access to LLNL computing capability.

\section{Program Components}

\section{Carbon Management}

Carbon capture and storage (CCS) has emerged as a key technology pathway to significantly reduce greenhouse gas emissions, particularly geological storage. Improved understanding of CCS economics, politics, and capture engineering has recently focused attention on the practical aspects of storage and its associated uncertainties. Concerns center on questions of risk of leakage from deep targets, both in terms of local and global risks. These concerns include both short- and long-term aspects, including direct health, safety, and environmental risks, the long-term fate of $\mathrm{CO}_{2}$ in the subsurface, and the overall efficacy of CCS as an emissions reductions strategy. Basic scientific questions regarding the processes associated with storage, the effects of subsurface heterogeneities (both stratal and structural), and handling of risk and uncertainty remain central. Such questions continue to drive interest in monitoring, measurement, and verification technologies (MMV). MMV suites will be required in some fashion to understand subsurface processes, underpin a regulatory framework, recognize leakage before and after surface escape, and even inform financial and liability decisions on individual storage sites.

From these concerns, LLNL has chosen to focus on three primary research areas in carbon storage: numerical simulation of storage, explicit risk characterization, and improved and novel MMV techniques. We are greatly expanding our numerical modeling efforts and subsurface simulation expertise in order to better quantify and circumscribe risk aspects. This includes better geochemical and geomechanical coupling, addition of hydrocarbon and co-contaminant equations of state, and dramatic increases in computational and numerical capabilities. New output arrays will include maps and rastor volumes that can be used for both deterministic and probabilistic risk assessments. 
In order to better understand the nature of potential leakage risks, we have studied natural and engineered systems to understand and constrain potential worst-case scenarios.

Currently, we focus on the Crystal Geyser site in Utah, where a poorly completed well has erupted $\mathrm{CO}_{2}$ episodically for 70 years. Our estimates of flux and concentrations suggest that this site is a good analog for well leakage large-volume storage sites. We have carried out long term measurements of $\mathrm{CO}_{2}$ concentrations at the Crystal geyser site and are now analyzing those to assess the potential leakage consequences from this worst case scenario.

Our MMV efforts focus on two topics. The first is methods that are low-cost, noninvasive. These include electrical methods (ERT and EMIT), surface deformation records (Tilt, GPS, InSAR), other methodologies. These methods provide data that seismic methods do not, and often provide time-series information with much higher sampling rates. The second topic is integration of MMV data streams. Our preferred approach involves stochastic integration and inversion, where data streams are explicitly compared using a Monte-Carlo, Markov chain approach to Bayes theorem. We are looking at how to assess the needs of a surface monitoring array as a function of climate, population, and terrain. The goal is to construct a methodology for planning sites in a variety of settings. Initial tests have been carried out using data from an industrial $\mathrm{CO}_{2}$ flood at Salt Creek, WY, and will expand with a new data sharing agreement with Chevron and Pinnacle Technologies Inc. Initial results with these and synthetic data sets show that new insights of subsurface carbon flows can be gained where working with individual capabilities can not attain the same results.

We have had considerable success in bringing LLNL capabilities to large scale demonstration projects in carbon sequestration. Jim Johnson has been Theme Area Coordinator for geochemistry at the Weyburn field and is currently forming a work plan and work team to continued study of the long term effects of sequestration. Julio Friedmann is chair of the technical advisory committee to CO2SINK in Germany and serves on the FutureGen advisory committee. We hope to build on these leadership positions to additionally engage projects across the world. This year, LLNL became a member of the DOE-sponsored ZERT research consortium, and received funding to integrate results in subsurface and atmospheric modeling and risk assessment. Finally, LLNL continues to play an important role in the WestCARB regional partnership in carbon sequestration and has joined two other regional partnerships - the Southeastern partnership (SeCARB) and the Midwest partnership (Illinois Basin).

Although Carbon Management has focused on the applied science of storage, we have continued work in carbon capture and separation as well. We have continued our work in advanced membrane development using SLIP technology and formed an eight company consortium to develop a commercial platform for post-combustion capture. We have also begun new work on novel capture approaches, including a new LDRD project using desalinization technology for carbon capture and combining accelerated limestone weathering with injection of co-produced water. We hope to expand this aspect of the program over the next year in partnership with DOE HQ, LANL, NETL, and nongovernmental entities. 


\section{PCMDI, Climate and Carbon Cycle}

The PCMDI, climate and carbon cycle program area (PCCC) seeks to answer questions of national need in climate science and the carbon cycle, with special focus on the fate of carbon in the earth system and its relationship to climate change. A strategic theme of this program is to advance our understanding of the environmental consequences from energy production/use within the context of natural variability in carbon and climate processes. Research includes global climate change and its regional ramifications, atmospheric chemistry and aerosols, atmospheric radiation and cloud physics, ocean dynamics and biogeochemistry, carbon-cycle science, climate model diagnosis and analysis, and climate change detection. PCCC carries out its research using detailed climate simulation analysis tools, high performance comprehensive climate-carbonchemistry models, and careful linking to laboratory experiments, field campaigns, climate observations.

The PCCC anchor program is the Program for Climate Model Diagnosis and Intercomparison (PCMDI). Three other larger and DOE-driven projects are the Atmospheric Radiation Measurement (ARM) data infrastructure project, the Climate Change Prediction Program (CCPP)/ARM parameterization testbed (CAPT), and the Scientific Discovery through Advanced Computing (SciDAC) climate modeling project. The goal of the PCMDI is to collaborate with the global climate modeling community by developing standardized diagnostic methods and innovative evaluation tools to assess the scientific quality of climate simulations, thereby enabling improvements in climate model formulation and climate prediction. This program has been a primary component in the climate change research portfolio in the Office of Biological and Environmental Research (OBER) in DOE for more than a decade.

A large effort this year for PCMDI has been the archiving and data management activities for the currently working IPCC Fourth Assessment Report. PCMDI archives have housed over 60,000 files containing climate simulation results from 21 models across the climate community. All data management is handled by PCMDI and so far, they have achieved 60 Tbytes in data requests and dissemination. This data archiving and management has been done via the Earth System Grid - a data management tool developed by PCMDI in partnership with NCAR and other DOE labs. The ARM (Atmospheric Radiation Measurement) project at LLNL continues to coordinate ARM data archival and distribution as well as interacting with the Science Team in analyzing ARM data. Additionally, LLNL scientists (Steve Klein and Cathy Chuang) have become more involved in ARM science activities with funded projects in aerosol parameterizations and cloud physics along with a brand new project in partnership with other DOE labs to examine the Multi-Scale Modeling Framework (MMF) as a means to provide a more realistic representation of cloud processes and physics. The CAPT program is an innovative project of the PCMDI that ties together the diagnostic/analysis capability of the PCMDI with ARM data available via LLNL's role in data infrastructure. The idea is to initialize a climate model simulation using ARM data and to integrate the climate model in a forecast mode (i.e., short time scale). Careful examination of the climate model simulation through continued comparison to ARM data provides insight into 
climate model performance. Over the past year, the CAPT testbed has completed its implementation of the AM2 climate model from the NOAA GFDL laboratory.

The Scientific Discovery through Advanced Computation (SciDAC) program at DOE is focused on a partnership with NCAR to advance the next generation of NCAR climate models. Philip CameronSmith has successfully completed simulations with a small chemical mechanism that efficiently represents the primary ozone production and loss mechanisms; analysis of the results is underway. In close collaboration with NCAR and DOE partners, we have also implemented a sulfur mechanism and carbon cycle model that enables the interactive creation of sulfate aerosols from both land based $\mathrm{SO} 2$ emissions and ocean based DMS emissions as well as cycling of carbon across landatmosphere-ocean boundaries.

To further our efforts in regional climate we have delivered to Scripps Institute for Oceanography high resolution multi-century coupled climate simulation results that will be the basis for climate change detection at regional scale. Never before has such a long and high resolution ( 1 degree) coupled simulation been completed. This length and resolution of simulation will allow a complete understanding of the internal modes of variability at regional scale.

\section{Water and Environment}

The Water and Environment Program (WE) area's mission is to meet the Nation's needs for science and technology to understand, secure, sustain and protect its water and environmental resources. We focus on managing the impacts of energy usage and production, defense and intelligence activities, and national security issues related to water and the environment.

Our approach includes:

(a) Scientific research to understand and predict how natural and anthropogenic processes impacts water and environmental systems and the consequences of change.

(b) Science and technology development to sustain water supplies to meet demand now, and in a future impacted by climate change, political and societal change, and in recognition of the health and environmental impacts of emerging contaminants.

(c) Analytical tools and technology development to protect resources against destructive rates of use and pollution, including terrorist weapons, and to find new or better ways to monitor and treat impaired resources.

Where LLNL expertise can be of unique assistance to public agencies, industry, and academia, we seek partnerships and collaborations.

The Marshall Islands Dose Assessment and Radioecology Program provides individual and environmental measurement data and dose assessments to characterize current 
radiological conditions and minimize exposure of resettled and resettling populations in areas affected by U.S. nuclear testing in the Marshall Islands for DOE's Office of Health Studies. LLNL's program is accomplished through activities directed towards supporting individual radiological protection programs in whole body counting and plutonium bioassay, performing analyses on environmental samples collected during field missions, providing verification monitoring of radiological conditions in support of the resettlement program, and publishing reports or otherwise supporting DOE's informational needs in helping protect the health and safety of people living in the Marshall Islands. While the program cooperates with many institutions, the primary external collaboration is with the Joint research Center Institute for Transuranium Elements (ITU) of the European Commission; this laboratory has been providing SEM and $\mu \mathrm{XRF}$ as well as other particle characterization studies on isolated radioactive aggregates.

This year has marked the start of a new mission in the Marshall Islands, with activities focused on the resettlement of Rongelap. LLNL's recommendations for site preparation for effective protection of human health in residential areas are being followed. The village area is being cleared, and construction has begun. Key elements of LLNL's 20052006 environmental missions include environmental sampling, sampling of food crop products and verification monitoring of external gamma exposure rates. A novel approach has been developed to assess potential exposure from food collections in other locations; this "pantry sampling" approach will provide information regarding the potential exposure from a key source, one with strong cultural links. Other measurements will help assess key environmental or dietary factors that could potentially change the total exposure from both internal and external sources.

WE continues to support the Energy Water Nexus activities at both the federal and state level. This effort, started under the Water Initiative, involves participation in a multilaboratory working group, actively supporting the establishment of a DOE energy and water security program. This year, we, along with partner DOE labs, have been funded to create a roadmap articulating the national and regional needs and technology gaps, that such a program could address. The proposed national program would be in the Department of Energy and would include regional centers coupling National Laboratory and university teams dedicated to water research and technology development tasks to address the national needs described by the roadmap. On the state level, the California Energy Commission has taken steps to identify the state's water-energy relationship; LLNL staff participated in the development of the CEC's California Water-Energy Relationship Staff Paper, prepared in support of the State's 2005 Integrated Energy Policy Report (IEPR). It highlights many key issues and identifies areas for technology and policy development. Also begun under the Water Initiative, WE took a leadership role in forming a Center for Water Supply Prediction Science with support from the Association of California Water Agencies (ACWA) and lead federal, state and local water agencies, involving the key academic researchers investigating climate change in California. On the nitrate contamination front, LLNL's Water Initiative work lead to an expansion of our role in the State's GAMA program for specific studies involving nitrate. In addition, a joint proposal (with Sustainable Conservation) addressing the application and performance verification of improved dairy management practices has been selected for funding by the State's Water Quality Control Board's Dairy Water Quality Grant 
Program. We have also had success in advancing the use of selective membranes for efficiently treating impaired water and seawater for desalination. Our approach combines molecular modeling and new synthesis methodologies, with promising results in developing new energy-efficient membranes for selective treatment of impaired waters. This Water Initiative-supported effort has lead to joint proposals between LLNL and industry/agencies. A project for a novel approach to desalination has been selected for funding under California's Prop. 50; another is under consideration for a hybrid approach enhancing ion exchange with electrodialysis. Our modeling codes are being applied for use in diverse applications as aligned carbon nanotubes and the design of virus detectors. The USBR has expressed interest in partnering with LLNL in part due to this work.

LLNL continues to support the Department of Interior's Bureau of Reclamation in developing an assessment of the groundwater resources in California's Imperial Valley, which may provide additional water options to consider in solving the Salton SeaImperial Valley water equation. Such an assessment requires the integration of a vast assortment of descriptive geologic, hydrologic, chemical, and climatic data related to the regional groundwater aquifers and the occurrence, movement, production, and quality of groundwater, with knowledge of related geologic, hydrologic, chemical, and climatic processes. For the Salton Sea area, much of this information already exists, but is in the hands of multiple public and private entities, disparate, focused on specific purposes, and often proprietary. In the first year, LLNL's team developed a database, integrating historic and recent data obtained in the region. This database is already serving to increase cooperation by different agencies, an important achievement in itself. The next steps involve developing a quantitative understanding of the key flows and fluxes in the region, and to highlight opportunities and constraints regarding use of the groundwater resource and its sustainability. This is particularly important in the East Mesa area, where significant losses from unlined canals have created a nearly century-old infiltration experiment.

WE depends on PI-driven research as the basis for successful program contributions, such as our historic strengths in fate and transport in environmental systems providing the underpinnings for our environmental management programs. EED manages the BES program in geosciences for LLNL, a program sponsored by the DOE Office of Science. The mission of this program is to develop a quantitative and predictive understanding of geologic processes related to energy and environmental quality. Reactive transport in geologic systems is the unifying theme of this research program. This subject bears on the disposal of radioactive waste, transport of contaminants, migration of hydrocarbons, and chemical evolution of the crust and mantle. The program comprises experimental programs to quantify the parameters required for tomographic observations of subsurface fluids, fundamental dissolution and precipitation kinetics and equilibria, and the geophysical theory required to invert field- based observations.

This year one investigation made a significant advance in understanding the kinetics of mineral dissolution. Dissolution rate data show apparent serious inconsistencies that cannot be explained by the largely empirical kinetic "laws."' We show that mineral dissolution can, in fact, be understood through the same mechanistic theory of nucleation developed for mineral growth. By generalizing nucleation rate equations to include 
dissolution, we arrive at a model that predicts how quartz dissolution processes change with undersaturation from step retreat, to defect-driven and homogeneous etch pit formation. This finding reveals that the "salt effect," recognized almost 100 years ago, arises from a crossover in dominant nucleation mechanism to greatly increase step density. The theory also explains the dissolution kinetics of major weathering aluminosilicates, kaolinite and $\mathrm{K}$-feldspar. In doing so, it provides a sensible origin of discrepancies reported for the dependence of kaolinite dissolution and growth rates on saturation state by invoking a temperature-activated transition in the nucleation process. Two new FY06 projects expand upon mineral dissolution kinetics investigating (1) the effects of aluminum in inhibiting mineral dissolution, and (2) the effects of fluid chemistry on stress corrosion cracking.

\section{Energy Systems}

The mission of the Energy Systems (ES) program area is to assure that the nation's future energy demands can be met in an environmentally responsible manner. We will do this by:

- Increasing the efficiency of existing energy technologies while minimizing their environmental impact by optimizing energy systems and improving conversion efficiencies in engines and fuel cells

- Reducing environmental impact of existing energy technologies through improved combustion mechanisms and removal of greenhouse emissions through new fuels

- Developing new environmentally responsible technologies

- Partnering with industry to commercialize our technology

Our Homogeneous Charge Compression Engine (HCCI) activities continue to be a focal point towards improved fossil fuel combustion efficiencies with the production of fewer emissions. This technology provides a more uniform combustion of fuel via compression ignition (not via sparc ignition) such that fuel mixtures and temperatures can be more completely managed and hence, NOx emissions can be reduced. Over this year, ES has demonstrated an operational $200 \mathrm{~kW}$ natural gas stationary power source using HCCI technology. In doing so, Dan Flowers and Salvador Aceves have brought together a series of accomplishments over the past 2 years that have (1) implemented intake manifold design that allows for cylinder-by-cylinder temperature control, (2) developed and implemented fuel-air control for ultra-lean operation, (3) developed and demonstrated HCCI-mode startup strategy, and (4) integrated supercharger boost system. Research on this system will continue to investigate the use of different fuels.

Transportation remains a major use of fossil fuel and improving efficiencies in the transportation sector is important to reducing greenhouse gas emissions. Within the transportation sector, class 8 heavy trucks use $11 \%$ of US petroleum. Within that, $65 \%$ of the energy used is to overcome drag at highway speeds. Using LLNL's computational 
power and advanced Computational Fluid Dynamics (CFD) models, ES (Rose McCallen and Kambiz Salari with others) have continued to lead a consortium of DOE Labs, academia, and industries towards a goal of $25 \%$ reduction in drag. The project has identified the technologies that can obtain these goals (truck base treatments, trailer skirts, and cap splitter plates), but much more work is needed to more completely understand the physics so that less obtrusive devices can be designed and implemented.

Our research on hydrogen focuses on storage capacity and storage safety. Storage of hydrogen has various advantages such as high volumetric and gravimetric density and low adiabatic expansion energy; however, suffers from high evaporative losses and high liquefaction costs. Activities at LLNL have addressed these issues by developing and testing cryogenic pressure vessels. Cooling of hydrogen increases its safety since energy release during a sudden failure is strongly reduced at lower temperatures. Salvador Aceves and Gene Berry have lifecycle tested conventional pressure vessels at cryogenic temperatures with no loss in performance over an equivalent 200,000 miles of use. They have demonstrated flexible refueling of insulated pressure vessels in a converted truck at LLNL and completed an extended 6 month test in Palm Springs. We have just completed the purchase of a hydrogen fueled Toyota prius in which we will be testing a next generation of hydrogen storage tanks. These tanks are lighter, more compact, and are more able to conform to automobile space requirements.

For years, LLNL has led the development of a fuel cell that directly converts carbon to electricity and $\mathrm{CO}_{2}$. The direct carbon fuel cell (DCFC) combines high conversion efficiency with a pure $\mathrm{CO}_{2}$ stream, thus serving both as a power supply technology and a capture device. This year, LLNL has licensed the DCFC technology to Contained Energy, Inc., which is working to commercialize it. This effort includes a $\sim \$ 700 \mathrm{k}$ CRADA to develop an alpha prototype of a direct carbon battery. 